\title{
Smooth, Low-Resistance, Pinhole-free, Conformal Ruthenium Films by Pulsed Chemical Vapor Deposition
}

\section{Citation}

Wang, Xinwei, and Roy G. Gordon. 2013. Smooth, low-resistance, pinhole-free, conformal ruthenium films by pulsed chemical vapor deposition. ECS Journal of Solid State Science and Technology 2(3): N41-N44.

\section{Published Version}

doi:10.1149/2.003303jss

\section{Permanent link}

http://nrs.harvard.edu/urn-3:HUL.InstRepos:10121957

\section{Terms of Use}

This article was downloaded from Harvard University's DASH repository, and is made available under the terms and conditions applicable to Open Access Policy Articles, as set forth at http:// nrs.harvard.edu/urn-3:HUL.InstRepos:dash.current.terms-of-use\#OAP

\section{Share Your Story}

The Harvard community has made this article openly available.

Please share how this access benefits you. Submit a story.

\section{Accessibility}




\title{
Smooth, Low-Resistance, Pinhole-free, Conformal Ruthenium Films
}

\section{by Pulsed Chemical Vapor Deposition}

\author{
Xinwei Wang a and Roy G. Gordon* \\ Department of Chemistry and Chemical Biology, Harvard University, Cambridge, Massachusetts 02138, United \\ States
}

*Corresponding Author

gordon@chemistry.harvard.edu

${ }^{a}$ Current address: School of Advanced Materials, Peking University Shenzhen Graduate School, Shenzhen 518055, China. 
ABSTRACT: Ruthenium $(\mathrm{Ru})$ thin films were deposited by pulsed chemical vapor deposition with precursors bis( $N, N^{\prime}$-ditert-butylacetamidinato)ruthenium(II)dicarbonyl, ammonia and hydrogen. Low-resistance polycrystalline Ru films with bulk density were obtained. Good adhesion to $\mathrm{SiO}_{2}$ substrates was achieved by introducing a thin layer of WN in between the $\mathrm{Ru}$ and the $\mathrm{SiO}_{2}$. Ru films only $\sim 2 \mathrm{~nm}$ thick fully covered the WN layer without any pinholes. Deposition of Ru inside narrow holes showed that good conformality was obtained by lowering the deposition temperature. The film surface was smooth, and the rms roughness value did not increase too much after rapid thermal annealing at $700{ }^{\circ} \mathrm{C}$. 


\section{Introduction}

Ruthenium $(\mathrm{Ru})$ metal has many unique properties. It has a relatively high work function, its oxide, $\mathrm{RuO}_{2}$, is conductive, and it is compatible with many high- $\kappa$ dielectric oxides, such as $\mathrm{SrTiO}_{3}{ }^{1}$ and $\mathrm{TiO}_{2}{ }^{2}$ Hence, $\mathrm{Ru}$ is being considered for electrodes in dynamic random access memories (DRAM) ${ }^{2}$ and gate metal in metal-oxide-semiconductorfield-effect (MOSFET) transistors. ${ }^{3} \mathrm{Ru}$ can also be used as a seed layer for electrodeposition of copper interconnects. ${ }^{4}$ Many chemical processes use ruthenium as a catalyst. ${ }^{5}$ Preparing thin Ru films with good properties, such as high density, low resistivity, and pinhole-free smooth surfaces, has raised much interest in industry recently. Vapor deposition is a promising approach to obtain thin Ru films with high quality and uniform thickness even inside narrow features. Several Ru compounds have been studied as precursors for atomic layer deposition (ALD) and chemical vapor deposition (CVD). But many of them, such as $\mathrm{Ru}(\mathrm{Cp})_{2},{ }^{6} \mathrm{Ru}(\mathrm{EtCp})_{2},{ }^{4} \mathrm{Ru}(\text { thd })_{3},{ }^{7,8}$ bis $\left(2,4\right.$-dimethylpentadienyl)ruthenium, ${ }^{9}$ and bis $(2,6,6-$ trimethyl-cyclohexadienyl)ruthenium, ${ }^{10}$ need to react with $\mathrm{O}_{2}$ in order to deposit $\mathrm{Ru}$ films. This may cause some unwanted oxidation of conductive substrates, such as titanium nitride in DRAM electrodes or tantalum nitride diffusion barriers in microelectronic interconnects. Recently, several Ru cyclooctatetraene precursors were reported to deposit Ru films with $\mathrm{H}_{2}$ in a reducing ambient, ${ }^{\text {1" }}$ however, the reported resistivity of deposited Ru films is quite high, ${ }^{11}$ which may be due to a high-level carbon impurity from the precursors or to a low film density. Gordon and coworkers have synthesized an amidinate Ru precursor, bis(N,N'-di-tert-butylacetamidinato)ruthenium(II) dicarbonyl, which can react with $\mathrm{NH}_{3}$ to produce $\mathrm{Ru}$ films by $\mathrm{ALD}^{12,13}$ and also in a non-oxidizing ambient. ${ }^{13}$ However, the best film properties were obtained by including small amounts of oxygen in the ALD process. ${ }^{14}$

ALD is a very slow process, so we investigated the use of this precursor in chemical vapor deposition (CVD) conditions. In this paper, we used this amidinate precursor to deposit thin Ru films with a pulsed CVD method. We were able to obtain dense, low resistive, pure and conformal Ru films with smooth and pinhole-free surfaces. We further examined the conformality of Ru films deposited inside narrow holes, in which the films showed good step coverage.

\section{Experimental}

Pulsed chemical vapor deposition of ruthenium was carried out in a home-built tube reactor, with bis( $N, N$ '-di-tertbutylacetamidinato)ruthenium(II)dicarbonyl as the Ru precursor and ammonia and hydrogen gases as co-reactants. The ruthenium precursor was placed in a glass bubbler in an oven at $140{ }^{\circ} \mathrm{C}$ or $150{ }^{\circ} \mathrm{C}$, and it was delivered by nitrogen carrier gas during each Ru pulse. Ammonia gas flowed continuously at 2 Torr partial pressure while the doses of Ru precursor were delivered. During each Ru dose cycle, the valve that controls the Ru delivery was first opened for 1 second for delivering the precursor vapor, and then closed for 5 seconds to allow the re-vaporization of the Ru precursor to go to 
equilibrium. Approximately $170 \mathrm{~mL}$ volume of Ru precursor vapor diluted in nitrogen gas is delivered in each pulse. After a fixed number of $\mathrm{Ru}$ precursor pulses, 3 Torr of hydrogen gas was supplied for one minute. We added these $\mathrm{H}_{2}$ steps because we found that they produced denser and more conductive Ru films.

Thermal $\mathrm{SiO}_{2}$ substrates were used for Ru deposition. They had $300 \mathrm{~nm}$ of thermal oxide on Si (100), and were treated with UV/ozone for 5 minutes to remove surface organic contaminants before deposition. Considering that Ru metal normally does not bond well to thermal oxide substrate due to the relatively inert chemical property of thermal $\mathrm{SiO}_{2}$, an adhesion layer is necessary for those practical applications that need some strength of adhesion. In our experiments, a thin layer of WN (typically $1 \sim 10 \mathrm{~nm}$ ) was introduced before Ru deposition in order to increase the adhesion. The deposition of WN layers was carried out by ALD with bis(tert-butylimido)bis(dimethylamido)tungsten(VI) vapor and ammonia gas. Details of the WN deposition can be found in our previous work. ${ }^{15}$ The as-deposited WN is amorphous, and its surface can be oxidized by exposure to air. In order to avoid oxidation of the WN, in situ Ru deposition followed right after the $\mathrm{WN}$ deposition in the same reactor without any air break.

The crystalline phase of deposited $\mathrm{Ru}$ films was evaluated by electron diffraction (ED) inside a transmission electron microscope (TEM) (JEOL, Model JEL 2100). Film composition and number of atoms per unit area were determined by Rutherford backscattering spectroscopy (RBS) and X-ray fluorescence (XRF). Film thickness was measured by X-ray reflectometry $(\mathrm{XRR})$ for relatively thick films $(>8 \mathrm{~nm})$, and film density was calculated from the thickness and the number of atoms per unit area. For very thin films, thickness cannot be directly measured by XRR. We assumed these films had the same density as thick films that were deposited under the same conditions. Film chemical composition was also evaluated by X-ray photoelectron spectroscopy (XPS) (ESCA, Model SSX-10o). Film electrical sheet resistance was measured by a four-point probe station (Veeco Instruments, Model FPP-10o). Film surface roughness was examined by atomic force microscopy (AFM) (Asylum, Model MFP-3D). The adhesion energy of $\mathrm{Ru} / \mathrm{WN}$ to $\mathrm{SiO}_{2}$ substrate was

measured by the four-point bend method. ${ }^{16-18}$ Before the measurement, samples were deposited with o.13 $\mu$ m of sputtered aluminum, and then attached by high strength epoxy (EPO-TEK 353ND from Expoxy Technology) to a piece of dummy silicon water. The bonded wafers were cut into $50 \times 5 \mathrm{~mm}$ beams. Then, a notch was scribed at the center of each beam to initiate a crack.

\section{Results and Discussion}

A $7 \mathrm{~nm} \mathrm{Ru}$ film was deposited at $317^{\circ} \mathrm{C}$ on a SiN $\mathrm{x}_{\mathrm{x}}$ membrane TEM grid with a $2 \mathrm{~nm}$ WN coating for crystalline analysis. The TEM electron diffraction (ED) pattern (Figure 1) showed that all of the observed rings belonged to the hexagonal Ru phase, which is also the stable phase of bulk Ru metal at standard conditions. Another Ru film deposited on a planar 
substrate with the same deposition conditions was examined by XPS for chemical composition analysis. The XPS spectrum (Figure 2) showed that the Ru film was quite pure. Only Ru peaks were obviously observed in the spectrum, which ruled out having nitrogen or oxygen incorporated in the film. (We could not draw conclusions on carbon, since the $\mathrm{C}$ is peak overlaps with $\mathrm{Ru} 3 \mathrm{~d}$ peaks.)

The film density was also evaluated using the atom areal density data measured by RBS or XRF, and the thickness data measured by XRR. If only $\mathrm{Ru} / \mathrm{NH}_{3}$ pulses were used, the film density was $\sim 6 \mathrm{~g} / \mathrm{cm}^{3}$, only $\sim 50 \%$ of the bulk value. Adding doses of hydrogen $\left(\mathrm{H}_{2}\right)$ increased the film density up to the bulk value. Films with bulk density were achieved if a hydrogen pulse was added after not more than about $0.1 \mathrm{~nm}$ of Ru growth. For example, in the case of depositing Ru at 317 ${ }^{\circ} \mathrm{C}$, the growth rate was $\sim 0.05 \mathrm{~nm} /$ pulse so a $\mathrm{H}_{2}$ pulse was added after every $2 \mathrm{Ru} / \mathrm{NH}_{3}$ pulses. This optimal condition was intuitively reasonable, since $0.1 \mathrm{~nm}$ is about half the thickness of a monolayer, and the optimal condition suggested that the rearrangement of surface $\mathrm{Ru}$ atoms was necessary before a monolayer of deposition is completed. We tested Ru samples with different thicknesses (greater than $8 \mathrm{~nm}$, so that reliable thicknesses could be determined by XRR), and the density values were consistently around $12.13 \mathrm{~g} / \mathrm{cm}^{3}$, provided sufficiently frequent $\mathrm{H}_{2}$ doses were applied. These density values are very close to the bulk Ru density value $12.18 \mathrm{~g} / \mathrm{cm}^{3}$, which shows that dense Ru films were obtained with our approach. The exact mechanism by which $\mathrm{H}_{2}$ produces dense $\mathrm{Ru}$ films is still unclear. But, Ru is known as a good catalyst for ammonia synthesis from $\mathrm{N}_{2}$ and $\mathrm{H}_{2},{ }^{19}$ and the mobility of catalyst surface atoms may be enhanced during the catalyzed reaction, resulting in changing the catalyst microstructures. A similar process may happen in this case: $\mathrm{H}_{2}$ enhances the mobility of surface $\mathrm{Ru}$ atoms, and allows them to pack into denser structures with lower surface energy than a porous low-density film.

As a potential candidate for electrodes in microelectronics, the electrical properties of the thin Ru films are also important for most practical applications. We measured the sheet resistances of films with different thicknesses, and calculated their resistivity values by multiplying sheet resistance and thickness values. The resistivity and thickness values were plotted in Figure 3. As the film thickness increased, the resistivity decreased and approached to its bulk value $7.1 \mu \Omega$ cm; while as the film thickness decreased, the resistivity increased rapidly. This is mainly due to the increased probability of electron surface scattering as the film thickness decreases. A scattering-induced-resistivity model is used to quantitatively analyze the data. ${ }^{20}$ In this model, the resistivity follows a linear relation with the reciprocal of film thickness, and can be expressed as

$$
\rho=\rho_{0}\left(1+\frac{t_{0}}{t}\right)
$$


where $\rho$ is the thin film resistivity, $\rho_{o}$ is the bulk resistivity taking into account any effect from impurities, $t$ is the film thickness, and $t_{\mathrm{o}}$ is a characteristic length, which is related to the electron mean free path and scattering effects from grain boundaries, interfaces, and surfaces. As we plotted the resistivity versus reciprocal of thickness relation, and fitted with a linear model in the inset of Figure 3, we extrapolated the film resistivity to a value $\rho_{o}=6.9 \pm 1.9 \mu \Omega \mathrm{cm}$, which is consistent with the bulk value of pure $\mathrm{Ru}, 7.1 \mu \Omega \mathrm{cm}$. The agreement between these resistivity values shows that no impurities are present at high enough concentrations to increase the resistance. In particular, the carbon concentration must be low, although we could not measure it directly by XPS because of the overlap of the C peak with a Ru peak. The nearly bulk density of the films is also consistent with this result. Indeed, low-density Ru films grown without the hydrogen steps showed considerably higher resistivities. The fitted length $t_{\mathrm{o}}$ was $21 \pm 6 \mathrm{~nm}$.

The morphology of the film surface was also investigated. The AFM image (Figure 4) of a $9 \mathrm{~nm}$ Ru film showed that the film surface was fairly smooth with an rms roughness value of $0.28 \mathrm{~nm}$, or only $3 \%$ of the film thickness. Since small rms value does not guarantee that the film is pinhole-free, and pinholes could cause problems in practice, we also examined pinholes by an etching method. We used an etching solution that contained a mixture of $\mathrm{H}_{2} \mathrm{O}_{2}$, ammonia, and water with a volumetric ratio of $\left(30 \% \mathrm{H}_{2} \mathrm{O}_{2}\right)$ :(concentrated $\left.\mathrm{NH}_{3}\right): \mathrm{H}_{2} \mathrm{O}=1: 1: 5$. The etchant does not etch Ru films, but when there are pinholes through a Ru film, the etchant can go through the pinholes and attack the WN layer underneath. The place where the underlying WN is attacked by the etchant has a different brightness under SEM. In order to have enough contrast under SEM, each of the samples here had a relatively thick WN layer ( $\sim \mathrm{o} \mathrm{nm})$. Figure $5(\mathrm{a})$ shows a thin Ru film that did not fully cover the WN layer, while Figure 5 (b) shows that no pinholes were observed after a 10-minute etching of a thicker Ru film. With this method, we were able to find the minimum thickness required for Ru to fully cover the WN surface. Our results showed that many pinholes existed in a $1.3 \mathrm{~nm} \mathrm{Ru}$ film (Figure 5(a)), but no pinholes were observed in a $2.3 \mathrm{~nm}$ Ru film (Figure $5(\mathrm{~b})$ ), which shows that only about $2 \mathrm{~nm}$ ( 10 monolayers) of Ru is enough to fully cover the WN substrate.

Further, the adhesion improvement by introducing $\mathrm{WN}$ adhesion layer was confirmed by the four-point bend measurement. For a typical $\sim 10 \mathrm{~nm}$ Ru film with thermal oxide as the substrate, $6.0 \mathrm{~J} / \mathrm{m}^{2}$ of adhesion energy was observed with a $10 \mathrm{~nm} \mathrm{WN}$ adhesion layer, compared to only $0.8 \mathrm{~J} / \mathrm{m}^{2}$ without the $\mathrm{WN}$ layer. Also, delamination was found at the $\mathrm{WN} / \mathrm{SiO}_{2}$ interface, which shows that the adhesion between $\mathrm{Ru}$ and $\mathrm{WN}$ is even stronger than $6.0 \mathrm{~J} / \mathrm{m}^{2}$. If stronger adhesion is needed, one should focus on improving the strength of the $\mathrm{WN} / \mathrm{SiO}_{2}$ interface.

Step coverage is another very important criterion for some applications of Ru films. One of the most important potential applications is as an electrode material in DRAM structures, where Ru will be deposited inside hole structures. ${ }^{1}$ In order to obtain high conformality of deposition, lower deposition temperature and higher precursor vapor pressure are 
usually needed. ${ }^{21}$ Therefore, we examined the temperature dependence of the deposition rate as shown in Figure 6 . The data (black filled squares) suggested a typical CVD behavior. In the low temperature region (below $270{ }^{\circ} \mathrm{C}$ ), the deposition rate was limited by the surface reaction rate, and the logarithm of deposition rate followed a linear relation with the reciprocal of temperature; at higher temperatures, the deposition rate drops below the linear curve because diffusion starts to limit the growth rate. We also increased the precursor bubbler temperature from $140{ }^{\circ} \mathrm{C}$ to $150{ }^{\circ} \mathrm{C}$ in order to get higher vapor pressure. A similar temperature dependence behavior was obtained for deposition rate (green open squares in Figure 6), but with a higher deposition rate above $270^{\circ} \mathrm{C}$. Below $270{ }^{\circ} \mathrm{C}$, a higher bubbler temperature did not increase the deposition rate, suggesting that the surface reaction rate had already reached saturation with vapor from the bubbler at $140{ }^{\circ} \mathrm{C}$.

With the guidance of above observations, we deposited Ru inside narrow holes with an aspect ratio (AR) of 40 (AR is defined as the ratio of depth to the diameter of each hole). The diameter and the depth of each hole are $0.2 \mu \mathrm{m}$ and $8 \mu \mathrm{m}$, respectively. $\sim 2 \mathrm{~nm}$ of WN was deposited before Ru deposition to improve adhesion, since strong film-to-wall adhesion is preferred in practice for further fabrication steps, such as chemical mechanical polishing (CMP). We chose to set $150^{\circ} \mathrm{C}$ as the bubbler temperature, and lowered the deposition temperature. We found that depositing at $317{ }^{\circ} \mathrm{C}$ did not give any film growth on the bottom of the holes, but as we decreased deposition temperature, films became more and more conformal. And eventually the film deposited at $242{ }^{\circ} \mathrm{C}$ gave fairly high conformality as shown in its cross-sectional SEM image in Figure 7. As we have shown that $2 \mathrm{~nm}$ is the minimum thickness for Ru to fully cover the WN surface, in order to achieve a continuous pinhole-free Ru film near the bottom of an AR 40 trench, we should need to deposit only about 3 $\mathrm{nm}$ Ru on the top.

There are also some applications of Ru for DRAM capacitors, where Ru films have to experience a high temperature annealing process. ${ }^{1}$ During the annealing process, agglomeration could roughen the surface of the films. Therefore, we also measured the surface roughness of a Ru/WN film before and after rapid thermal annealing (RTA). The thicknesses of $\mathrm{Ru}$ and $\mathrm{WN}$ layers were $13 \mathrm{~nm}$, and $3 \mathrm{~nm}$, respectively, and the RTA was performed at $700{ }^{\circ} \mathrm{C}$ for 2 min. The surface morphology was examined by AFM (Figure 8), showing that the rms roughness value increased from $0.5 \mathrm{~nm}$ to $1.4 \mathrm{~nm}$ after RTA. Considering that the rms value after annealing was still much smaller than the film thickness, a slight increase in surface roughness may be acceptable for practical applications.

\section{Conclusions}

We were able to grow Ru thin films in a non-oxidizing ambient with bulk density, low resistivity, high purity and smooth surface morphology. Depositing a thin layer of WN before Ru deposition greatly increased the adhesion of the Ru 
film to $\mathrm{SiO}_{2}$ substrate. Only $\sim 2 \mathrm{~nm}$ of $\mathrm{Ru}$ film was needed to fully cover the WN layer without any pinholes. Deposition of $\mathrm{Ru}$ inside narrow holes was also investigated. Fairly good conformality was obtained by lowering the deposition temperature. And film roughness did not increase too much after $700{ }^{\circ} \mathrm{C}$ RTA. The properties we obtained would satisfy many requirements of potential applications of thin films of ruthenium.

\section{Acknowledgments}

The ruthenium precursor was supplied by the Dow Chemical Company. We thank Prof. Joost Vlassak for the use of his system for mechanical testing of thin films. This work was performed in part at the Center for Nanoscale Systems (CNS) at Harvard University, a member of the National Nanotechnology Infrastructure Network (NNIN), which is supported by the National Science Foundation under NSF award no. ECS-0335765. 


\section{References}

S. K. Kim, S. W. Lee, J. H. Han, B. Lee, S. Han, and C. S. Hwang, Adv. Funct. Mater. 2o, 2989 (2010).

S. K. Kim, G. J. Choi, S. Y. Lee, M. Seo, S. W. Lee, J. H. Han, H. S. Ahn, S. Han, and C. S. Hwang, Advanced Materials 20,1429 (2008).

V. Misra, G. Lucovsky, and G. N. Parsons, MRS Bull. 27, 212 (2002).

O. K. Kwon, J. H. Kim, H. S. Park, and S. W. Kang, J. Electrochem. Soc. 151, G109 (2004).

A. Ozaki, Accounts Chem. Res. 14, 16 (1981).

T. Aaltonen, P. Alen, M. Ritala, and M. Leskela, Chem. Vapor Depos. 9, 45 (2003).

T. Aaltonen, M. Ritala, K. Arstila, J. Keinonen, and M. Leskela, Chem. Vapor Depos. 1o, 215 (2004).

S. K. Kim, S. Hoffmann-Eifert, and R. Waser, J. Phys. Chem. C 113, 11329 (2009).

K. Kawano, H. Kosuge, N. Oshima, and H. Funakubo, Electrochem. Solid State Lett. 1o, D6o (2007).

K. Gregorczyk, L. Henn-Lecordier, J. Gatineau, C. Dussarrat, and G. Rubloff, Chem. Mat. 23, 2650 (2011).

T. Ando, N. Nakata, K. Suzuki, T. Matsumoto, and S. Ogo, Dalton Trans. 41, 1678 (2012).

H. Z. Li, T. Aaltonen, Z. W. Li, B. S. Lim, and R. G. Gordon, Open Inorg. Chem. J. 2, 11 (2008).

H. Li, D. B. Farmer, R. G. Gordon, Y. Lin, and J. Vlassak, J. Electrochem. Soc., 154, D642 (2007).

H. Wang, R. G. Gordon, R. Alvis, and R. M. Ulfig, Chem. Vapor Deposition 15, 312 (2009).

J. S. Becker, S. Suh, S. L. Wang, and R. G. Gordon, Chem. Mat. 15, 2969 (2003).

R. Dauskardt, M. Lane, Q. Ma, and N. Krishna, Eng. Fract. Mech. 61, 141 (1998).

M. Lane, R. H. Dauskardt, A. Vainchtein, and H. J. Gao, J. Mater. Res. 15, 2758 (2000).

Y. Lin, J. J. Vlassak, T. Y. Tsui, and A. J. Mckerrow, Mat. Res. Soc. Symp. Proc. 795, 93 (2004).

R. Schlogl, Angewandte Chemie-International Edition 42, 2004 (2003).

S. M. Rossnagel and T. S. Kuan, J. Vac. Sci. Technol. B 22, 240 (2004).

A. Yanguas-Gil, Y. Yang, N. Kumar, and J. R. Abelson, J. Vac. Sci. Technol. A 27, 1235 (2009). 


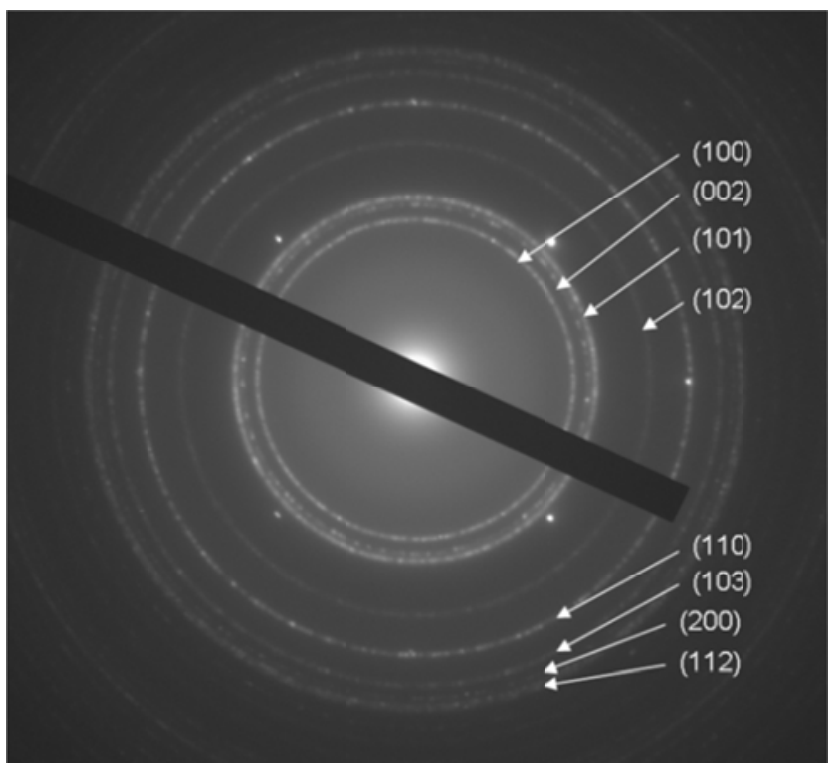

Figure 1. ED pattern of a $7 \mathrm{~nm}$ Ru film on a $\mathrm{SiN}_{\mathrm{x}}$ membrane $(50 \mathrm{~nm}) \mathrm{TEM}$ grid with $2 \mathrm{~nm}$ amorphous WN deposited just before the $\mathrm{Ru}$. The rings belong to the hexagonal Ru phase, and the discrete spots came from Si substrate, which was used for internal calibration. 


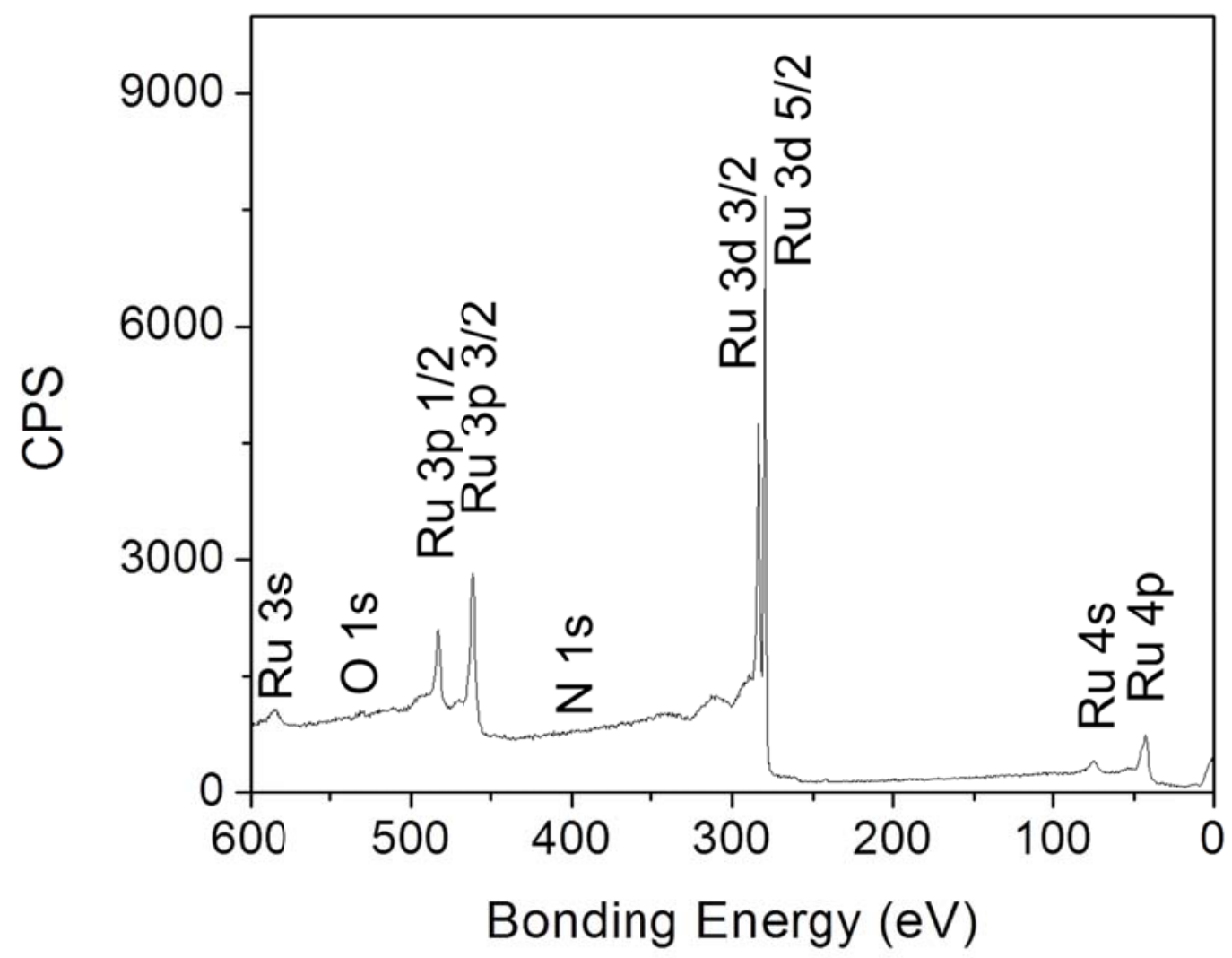

Figure 2. XPS showing the Ru film was free of impurities. Notice that we could not draw conclusions about carbon since the $C$ is peak overlaps with Ru 3d peaks. 


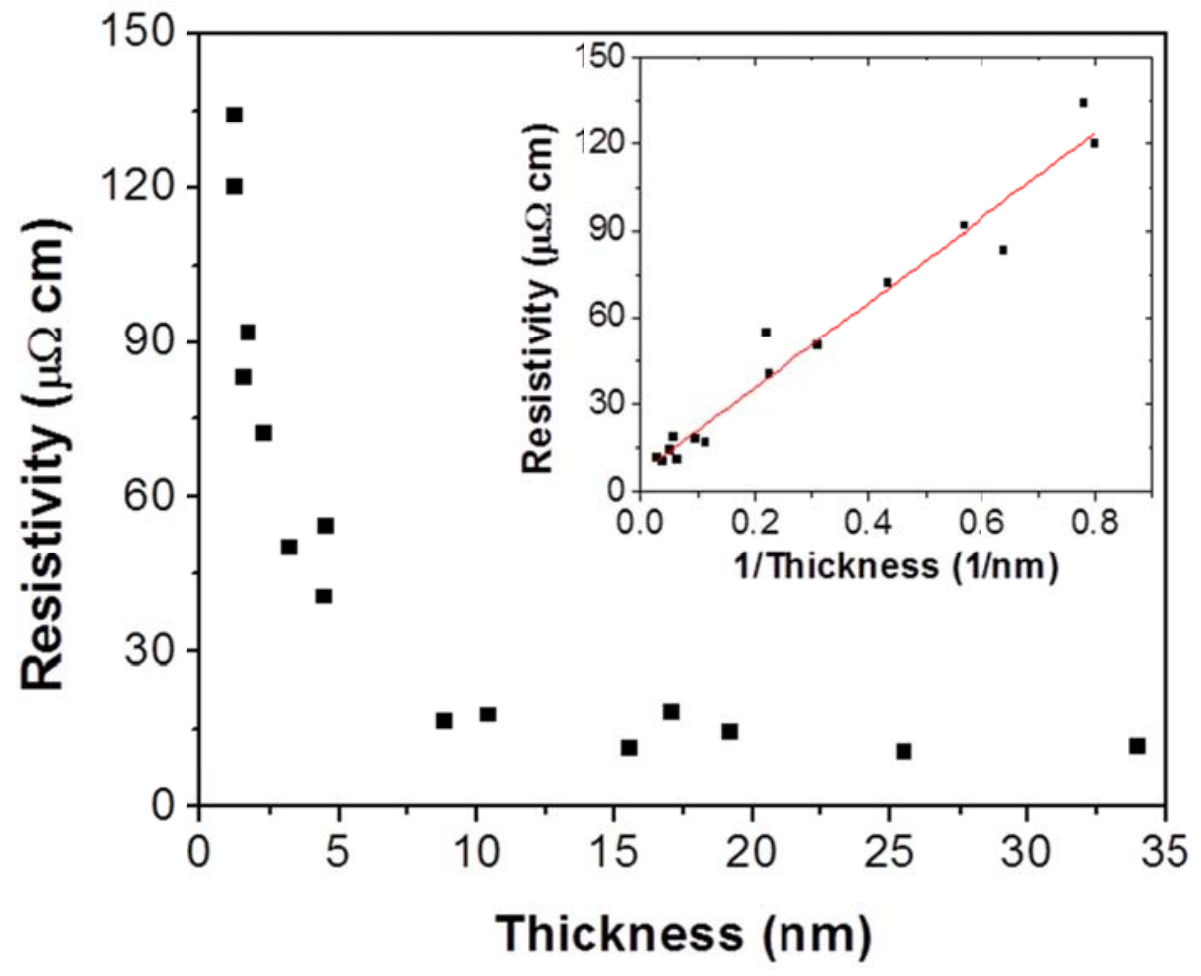

Figure 3. The relation between the Ru film resistivity and thickness. (Inset: the relation between resistivity and the reciprocal of thickness.) 


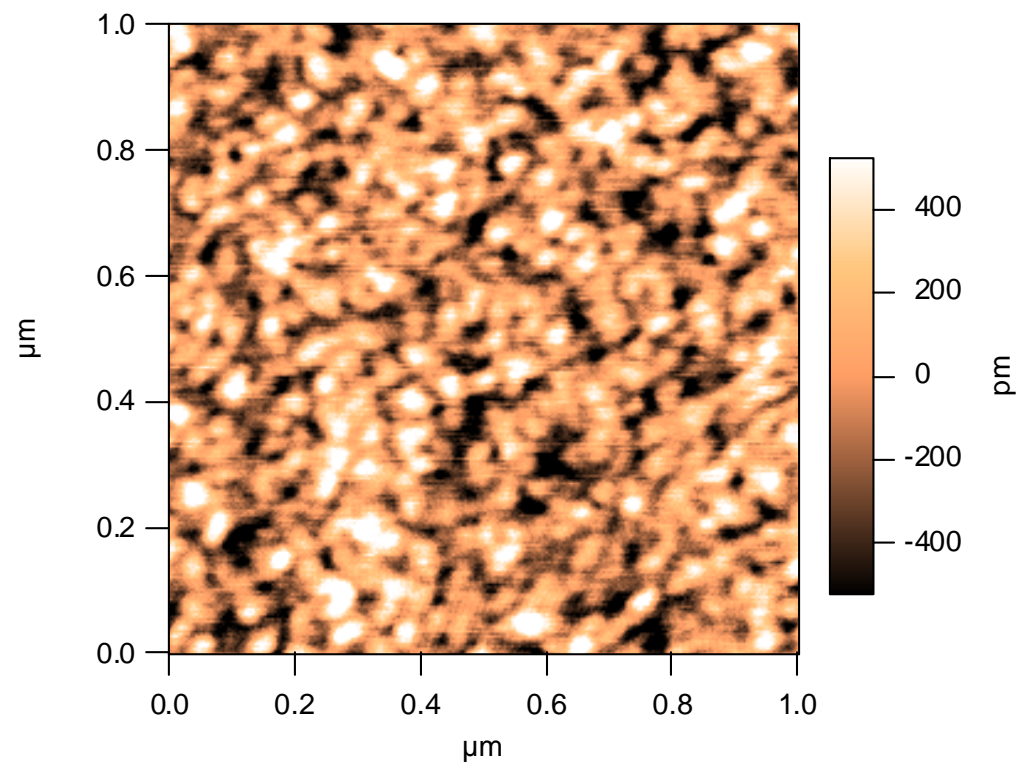

Figure 4. AFM image of $\mathrm{Ru} / \mathrm{WN}(\sim 9 \mathrm{~nm} / 1 \mathrm{onm})$ film on thermal $\mathrm{SiO}_{2}$ substrate. The rms roughness value is $0.28 \mathrm{~nm}$. 


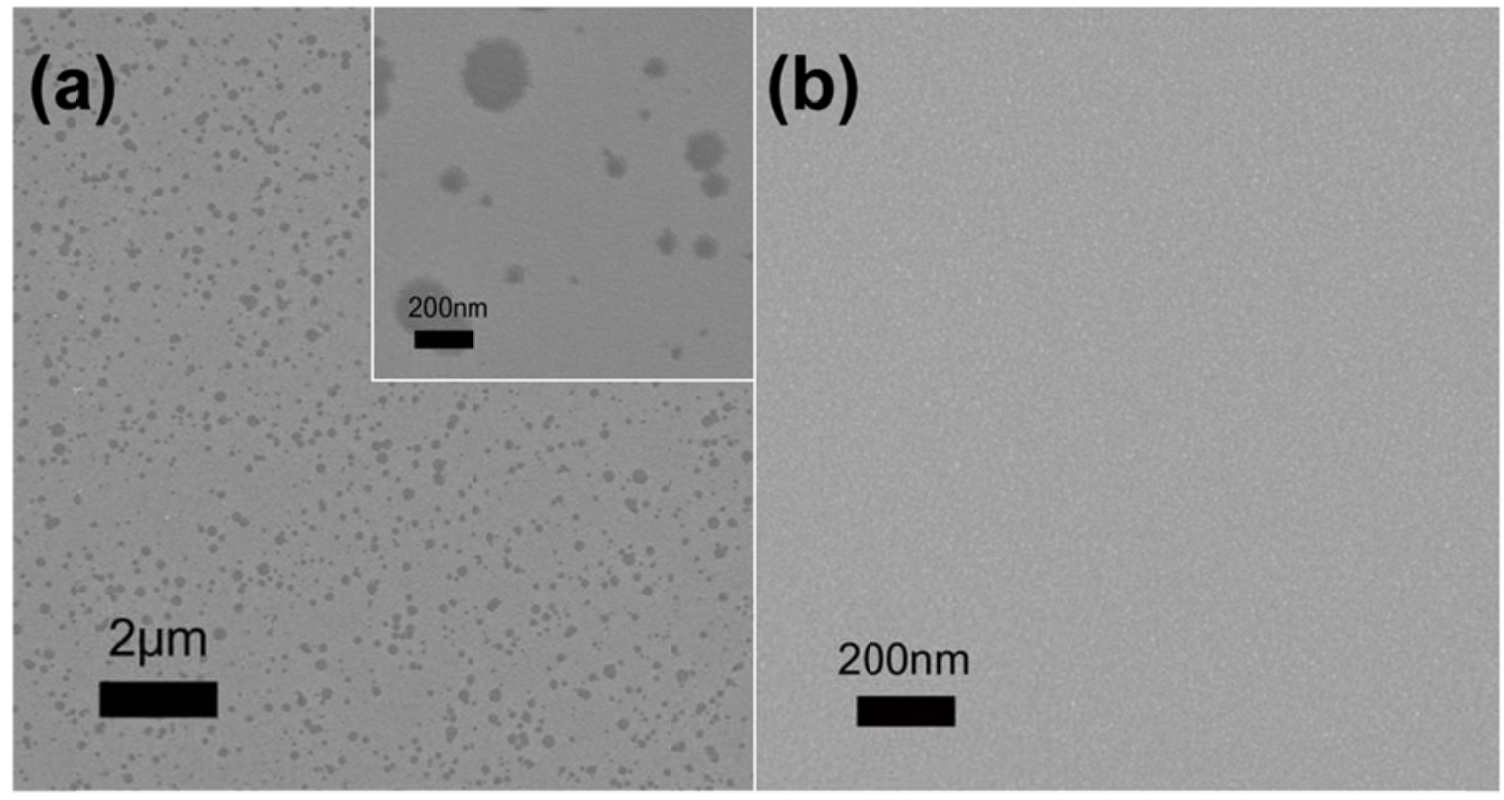

Figure 5. SEM images of Ru/WN samples after 10-minute etching in $\mathrm{H}_{2} \mathrm{O}_{2} / \mathrm{NH}_{3}$, which dissolves WN but not Ru. The sample with (a) $1.3 \mathrm{~nm}$ Ru on $10 \mathrm{~nm}$ WN showed many pinholes, while the sample with (b) $2.3 \mathrm{~nm}$ Ru on $10 \mathrm{~nm} \mathrm{WN}$ did not have pinholes. 


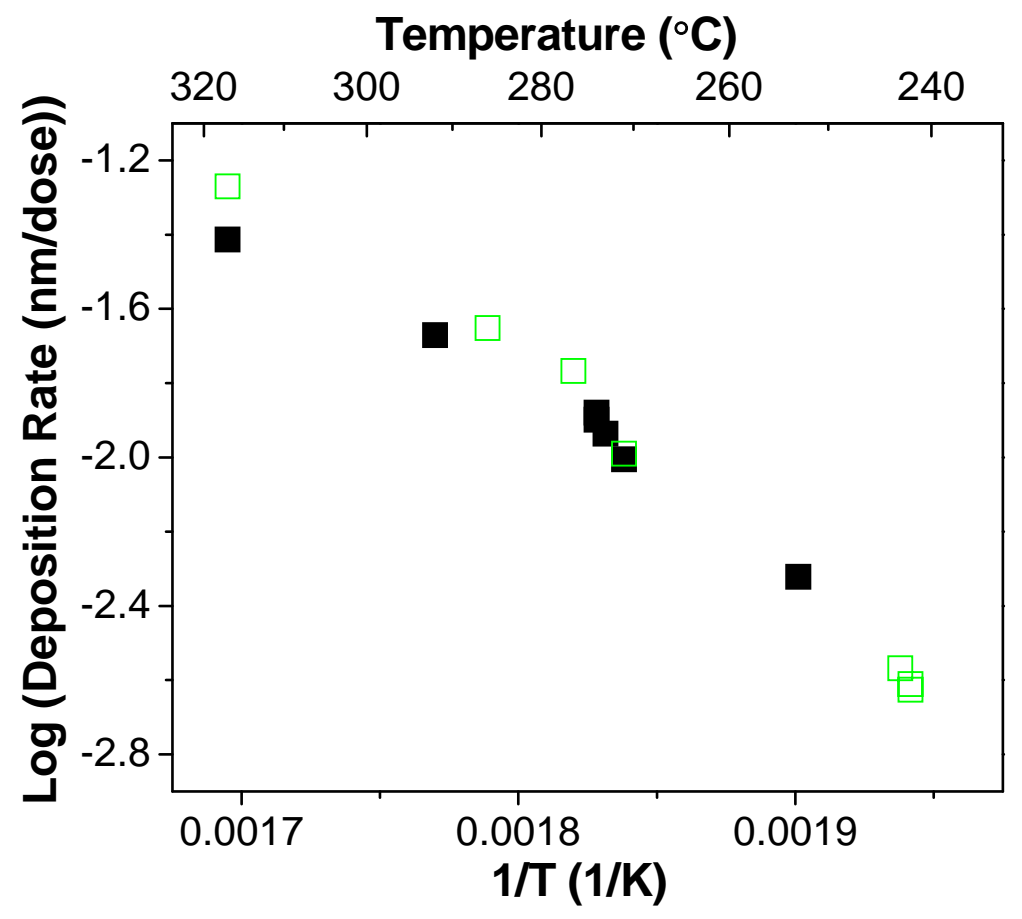

Figure 6. The relation of Ru deposition rate and deposition temperature. Black filled squares, and green open squares correspond to different bubbler temperatures, i.e. $140{ }^{\circ} \mathrm{C}$ and $150^{\circ} \mathrm{C}$, respectively. 


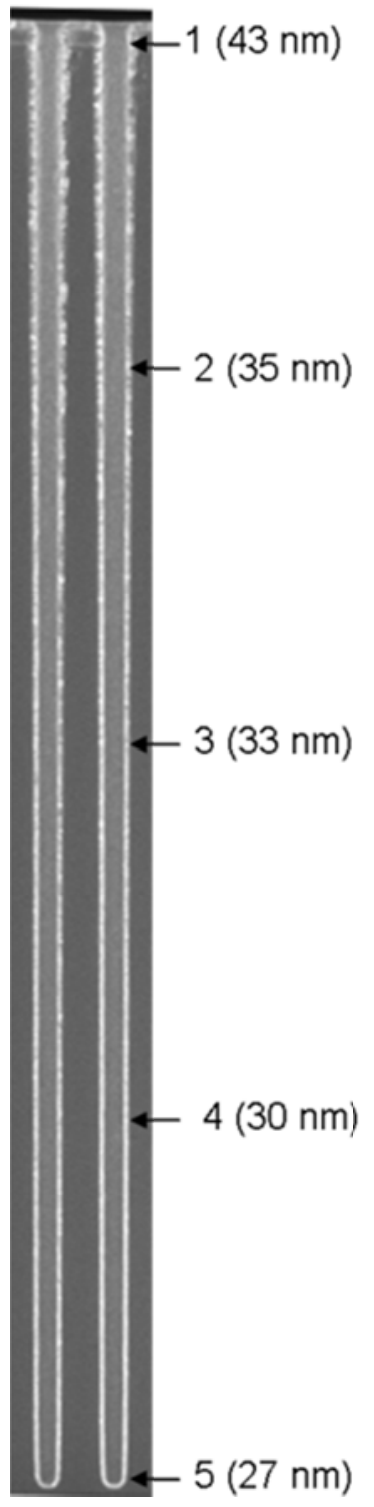

Figure 7. Cross-sectional SEM showing the conformality of Ru deposition. The holes are $0.2 \mu \mathrm{m}$ in diameter and $8 \mu \mathrm{m}$ in depth (aspect ratio is 40:1). $2 \mathrm{~nm}$ of highly conformal WN was deposited first, and then followed with Ru deposition at $242^{\circ} \mathrm{C}$. Values in parentheses are the film thicknesses at corresponding depths along the hole. 

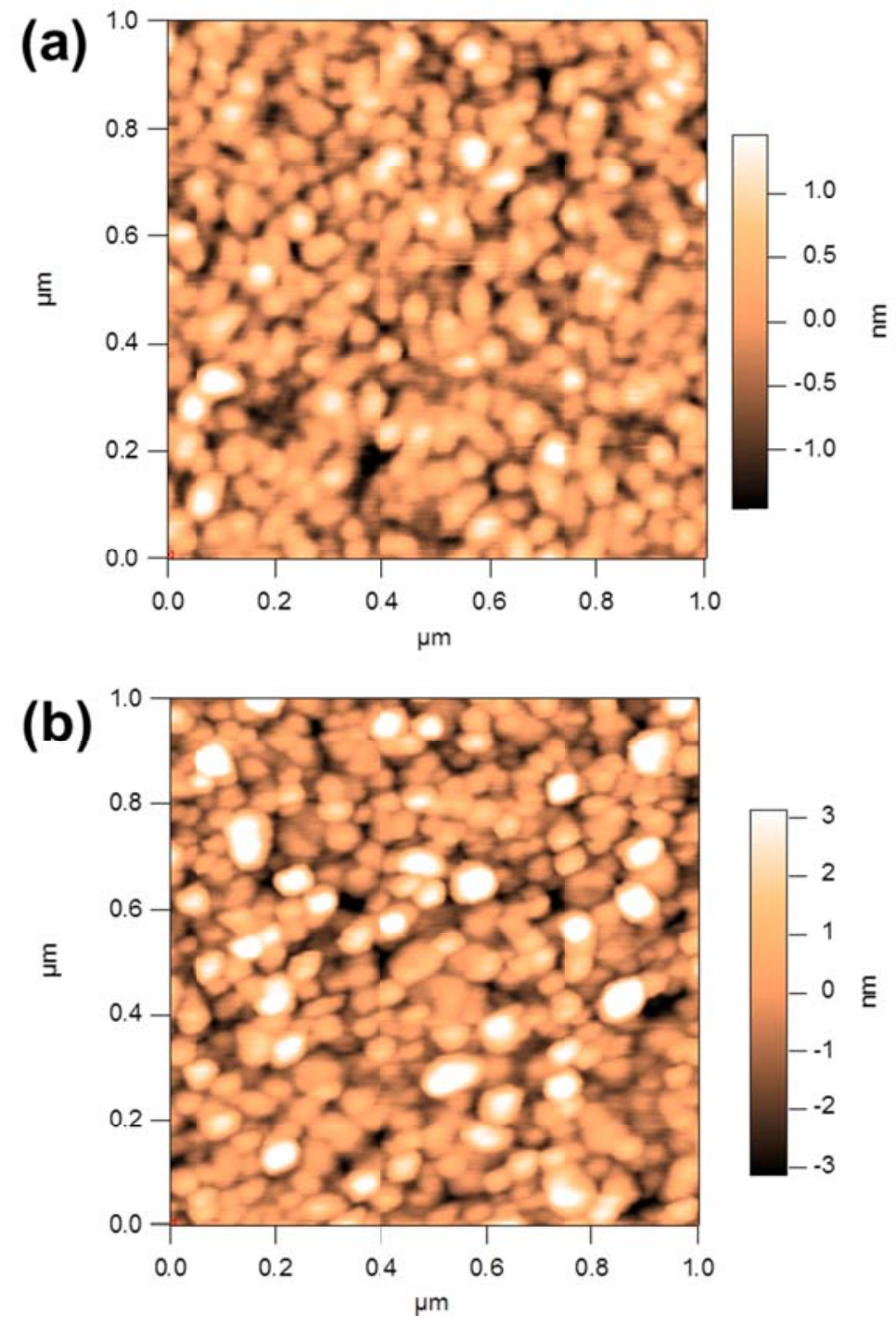

Figure 8. AFM images of $\mathrm{Ru} / \mathrm{WN}$ (13nm/3nm) film on thermal $\mathrm{SiO}_{2}$ substrate. The rms roughness values for (a) as-deposited film, and (b) 2 min $700{ }^{\circ} \mathrm{C}$ RTA film were $0.5 \mathrm{~nm}$, and $1.4 \mathrm{~nm}$, respectively. 